\title{
Corrosion Protection of Electrogalvanized Steel by Surface Treatments containing Cerium and Niobium compounds
}

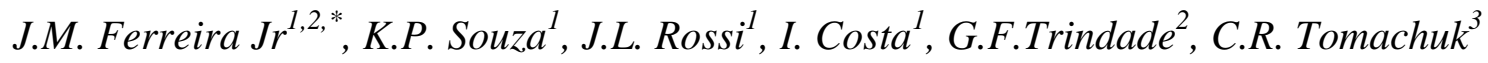 \\ ${ }^{1}$ Instituto de Pesquisas Energéticas e Nucleares - IPEN/CNEN-SP, Av. Prof. Lineu Prestes, 2242, CEP \\ 05508-000, São Paulo, SP, Brazil \\ ${ }^{2}$ University of Surrey, Faculty of Engineering and Physical Sciences, Guildford, Surrey, GU2 7XH, \\ United Kingdom \\ ${ }^{3}$ Engineering School of Lorena of the University of São Paulo (EEL-USP), Environmental and Basic \\ Sciences Department, Estrada Municipal do Campinho, s/n, 12602-810, Lorena, SP, Brazil \\ *E-mail: jose.ferreira@surrey.ac.uk
}

doi: $10.20964 / 2016.08 .19$

Received: 14 March 2016 / Accepted: 27 May 2016 / Published: 7 July 2016

In this work, new surface treatments for the corrosion protection of electrogalvanized steel have been evaluated. The aim was to search for chromium free treatments to replace those based on hexavalent chromium. Surface films were obtained by immersion in solutions containing salts for increasing conductivity, coating forming salts (i.e. cerium nitrate and niobium oxalate ammonium) and an organic complexing agent (2-butyne 1,4 diol propoxylate). The morphology and composition of the surface films formed were characterized by scanning electron microscopy (SEM) and X-ray Photoelectron Spectroscopy (XPS). The corrosion resistance of the treated surfaces was evaluated by electrochemical impedance spectroscopy (EIS) and their chemical composition was characterized by XPS. It was found that it consists of an organic coating with cerium incorporated. The electrochemical results suggested surface film increased the corrosion resistance of the electrogalvanized steel and similar protection properties to that of a chromate coating were indicated.

Keywords: electrogalvanized steel, corrosion protection, organic coating, cerium and niobium.

\section{FULLTEXT}

(C) 2016 The Authors. Published by ESG (www.electrochemsci.org). This article is an open access article distributed under the terms and conditions of the Creative Commons Attribution license (http://creativecommons.org/licenses/by/4.0/). 